\title{
PROJETO GUARDA AMBIENTAL MIRIM: UMA ANÁLISE CRÍTICA DAS DIFERENTES GESTÕES.
}

\author{
Maria Luíza Silva
}

Milena Ribeiro

\section{Orientadora: Simone Fadel}

\section{Introdução}

O presente artigo procede da pesquisa desenvolvida junto ao Núcleo de Estudos do Espaço da Baixada Fluminense (NIESBF) formado por docentes e discentes da Faculdade de Educação da Baixada Fluminense (FEBF), unidade acadêmica da Universidade do Estado do Rio de Janeiro (UERJ), onde procuramos apresentar os primeiros resultados da pesquisa dos bolsistas de Iniciação a Docência sobre Educação Ambiental em uma Unidade de Conservação.

Esta pesquisa tem como propósito ressaltar a importância da Educação Ambiental em Unidades de Conservação, onde esta precisa proporcionar mudanças de comportamentos e valores sociais, econômicos, culturais e ecológicos que procurem mostrar a importância da manutenção dessas áreas. As práticas educativas nas Unidades de Conservação devem superar a ideia romântica de natureza e ir além do pensamento de ambiente relacionado somente a ecologia, a educação proporcionada deve desenvolver e motivar a construção da cidadania e ajudar a entender a crise ambiental como um problema social que deve ser solucionado de forma inteligente através da participação comunitária.

Tomando o Parque Natural Municipal da Taquara como exemplo de Unidade de Conservação que tem um projeto de Educação Ambiental nossa pesquisa procura entender esse projeto em suas diferentes gestões e o tipo de educação ambiental que estas proporcionaram para as crianças do projeto e para a população do entorno.

O Projeto Guarda Ambiental Mirim é uma atividade de educação ambiental desenvolvida a 6 anos com crianças, entre 7 a 14 anos, da rede pública e particular de ensino, e que tem como objetivo, segundo a atual coordenadora do projeto, formar multiplicadores da consciência ecológica, não só dentro do ambiente escolar, mas também na comunidade em que vivem. O Parque Natural Municipal da Taquara (PNMT), local onde o projeto é realizado, está localizado no município de Duque de 
Caxias (RJ) ${ }^{1}, 3^{\circ}$ Distrito, sendo uma área de proteção integral criada em $11 \mathrm{de}$ dezembro de 1992 com base no $5^{\circ}$ artigo do Código Florestal que previa criação de Parques Municipais pelo Poder Público, de acordo com a Lei ${ }^{\circ}{ }^{9} .985$, de 18 de Julho de 2000, com cerca de 20 hectares de área, proporcionando a formação de um corredor ecológico com Área de Proteção Ambiental (APA) de Petrópolis e a Reserva Biológica (REBIO) do Tinguá. Deste modo, é neste local onde foi criado o único projeto de educação ambiental desenvolvido pelo município em uma de suas unidades de conservação.

O Guarda Ambiental Mirim, foi elaborado em $2005^{2}$ pela equipe responsável pelo Parque Natural Municipal da Taquara, onde foram elaborados materiais específicos para o projeto e se firmou importante parceria para a execução do mesmo. Após a mudança de governo, com as eleições municipais, ocorreu a troca de gestão do parque em $2009^{3}$, e consequentemente, mudanças com relação ao Guarda Ambiental Mirim, onde se destacam: o término do financiamento, algumas mudanças no conteúdo programático, no tempo de curso, o nome e a ampliação para as escolas estaduais. Apesar de não ser comum a continuidade de programas e/ou projetos na mudança de gestão governamental entre partidos opostos, afirma-se que o Projeto Guarda Ambiental Mirim sofreu mudanças no seu perfil, mas permanece como a proposta de ação de educação ambiental para a Unidade de Conservação.

Deste modo, procuraremos mostrar as mudanças realizadas e os motivos que levaram a permanência desse projeto, lançando mão das correntes da Educação Ambiental e das características do PNMT que levaram ao pensar, o desenvolver e a permanência do

\footnotetext{
${ }^{1}$ O município de Duque de Caxias está situado na Região Metropolitana do Rio de Janeiro e ocupa a Região da Baixada Fluminense. Segundo dados do Instituto Brasileiro de Geografia e Estatística (IBGE, 2009) o município responde por $27 \%$ do valor da produção do Estado, onde se encontram empresas importantes como Sadia, Transportes Carvalhão, Ciferal e IBF. Com relação ao Índice de Desenvolvimento Humano (IDH), o município ocupa a qüinquagésima - segunda posição contendo um dos maiores Produto Interno Bruto (PIB) do Brasil e uma população de 818.432 de habitantes.
}

Por questões administrativas, o município de Duque de Caxias se divide em 4 Distritos, que abrigam os diferentes bairros que compõem a cidade: 1ㅇdistrito (Centro); 2ㅇdistrito (Campos Elísios); 3ㅇ (Imbariê); 4o distrito (Xérém).

\footnotetext{
${ }^{2}$ A gestão de 2005-2008 corresponde a do prefeito Washington Reis.

${ }^{3}$ A gestão de 2009-2012 corresponde a do prefeito José Camilo Zito.
} 
Projeto Guarda Ambiental Mirim e analisar os dois momentos do projeto avaliando a metodologia a partir da sua interface com a localidade e os conteúdos abordados.

\section{Educação Ambiental: possíveis caminhos da concepção ambiental}

Para uma melhor compreensão e análise do projeto é necessário entendermos as concepções das práticas ambientais através de um panorama geral da inserção destas diferentes perspectivas no campo da educação, visto que elas nos direcionam para o tipo de educação ambiental que foi e a que está sendo desenvolvida no Projeto Guarda Ambiental Mirim, ao mesmo tempo em que entendemos melhor o tipo de multiplicador ambiental que está sendo formado.

O tema Educação Ambiental é uma realidade explícita na sociedade, visto que cada vez mais políticas públicas estão sendo traçadas sobre essa questão. Em âmbito internacional, a Educação Ambiental ganhou maior destaque com a Conferência das Nações Unidas sobre Meio Ambiente, em Estocolmo no ano de 1972, reconhecendo a Educação Ambiental como um elemento importante no combate a crise ambiental. Desde então, vem sendo produzido e construído conceitos e documentos que inserem a dimensão ambiental na educação, como na reunião intergovernamental sobre Educação Ambiental, ${ }^{4}$ ocorrida em Tbilisi (Geórgia) em 1977, e na Conferência das Nações Unidas sobre Meio Ambiente e Desenvolvimento (Rio 92), em que se reconheceu a educação como um elemento em constante construção.

Essas conferências e debates acerca da temática ambiental influenciaram no fato da Constituição Federal Brasileira ter propiciado uma maior institucionalização do tema, resultando na determinação da inserção da Educação Ambiental nos Parâmetros Curriculares Nacionais (PCNs) e na criação do Programa Nacional de Educação Ambiental (PRONEA) ${ }^{5}$, tornando-a um elemento essencial na educação nacional.

\footnotetext{
${ }^{4}$ Segundo Loureiro (2007), nessa conferência foi listado 41 diretrizes da educação ambiental. Entre elas, destacam-se o estudo dos planos de desenvolvimento social sustentável, a importância da totalidade para os aspectos ambientais, a compreensão da educação como um processo crítico que pode ser realizado em âmbito forma e não-formal e a abordagem da educação ambiental de maneira interdisciplinar.

${ }^{5}$ A sigla PRONEA é referente ao Programa instituído em 1994, enquanto a sigla ProNEA refere-se ao Programa instituído em 1999 (ProNEA,2003)
} 
Em 1999, foi publicado o Art.2 da Política Nacional de Educação Ambiental, onde educação ambiental caracterizou-se um componente essencial e permanente da educação nacional, devendo estar presente, de forma articulada, em todos os níveis e modalidades do processo educativo, em caráter formal e não-formal (ProNEA, 2003).

Dentro desse contexto, não podemos deixar de incluir as diferentes concepções de educação ambiental, elaboradas ao longo das diferentes conjunturas sócio-ambientais emergentes, onde segundo Rescheinky e Reigota (2002), a concepção construída de educação ambiental está diretamente relacionada à concepção de meio ambiente construída socialmente, sendo necessário às bases pedagógicas para a proposta que se espera desenvolver. Logo, a partir das diferentes idéias que constituem a educação ambiental destacamos duas vertentes opostas: a Educação Ambiental Conservadora e a Educação Ambiental Crítica, onde uma tem a intenção de manter o caráter do atual modelo sem transformar os valores e hábitos presentes na sociedade. Enquanto a outra tem a intenção de buscar um novo modelo e transformar a sociedade e suas atitudes. Essas diferentes concepções tentam se firmar na sociedade como modelos a serem desenvolvidos. Logo para entendermos as diferentes concepções, devemos entender a Educação Ambiental como:

[...] uma das dimensões do processo educacional. No entanto, podemos ter diferentes projetos educacionais que reflitam e sejam reflexos de diferentes "visões sociais do mundo", em um espectro que alcança das visões mais conservadoras às mais críticas. (GUIMARÃES, 2000,p.23).

A Educação Ambiental Conservadora dispõe da preservação dos recursos naturais intocados, protegendo-os da degradação humana, orientada por pensamentos que pouco contribuem para um diferencial na relação sociedade e ambiente, resultando em poucas atitudes que superem a crise ambiental vigente. Nessa concepção se observa um olhar voltado para o indivíduo, tornando-a uma educação transmissora de saber apenas, pois não se resolve o problema do atual modelo econômico, revelando uma educação individualista e comportamentalista.

A lógica da concepção conservadora apresenta um caráter compartimentado, onde as somas dos resultados das ações individuais levariam a transformação da realidade. A partir dessa característica ideológica fragmentada, Tanner (1978) desenvolveu alguns termos que resumem a perspectiva conservadora, como o fato de focar nas florestas, no solo ou na água, limitando-se a um único elemento natural e sua preservação; de sua 
perspectiva local, restringindo-se às fronteiras humanas os problemas ambientais; de seu aspecto rural, onde a natureza deve estar longe do alcance humano e de sua capacidade de destruição, enfatizando os aparatos tecnológicos para enfrentá-la; do seu caráter terrestre, preocupando-se somente com os aspectos relacionados à litosfera; das soluções unilaterais, voltadas apenas a um dos problemas, não abrangendo uma visão totalitária; e da sua relação com as ciências biofísicas, em que a questão ambiental depende somente da resposta dessas.

Deste modo, observa-se que a Educação Ambiental Conservadora privilegia uma visão da natureza que cria uma idéia de domínio e superação do homem e um distanciamento maior dele com o meio ambiente:

entendendo o problema ambiental como fruto de um desconhecimento dos princípios ecológicos que gera "maus comportamentos" nos indivíduos, cabendo à educação conservacionista, um instrumento de socialização humana perante a natureza, criar "bons comportamentos". (LAYRARGUES, 2000, p.89)

Entretanto, outro caminho da educação ambiental é a Educação Ambiental Crítica que se refere à relação do homem como parte da natureza, em que os problemas ambientais estão atrelados ao modelo econômico, baseado no consumismo e no cartesianismo impregnado no senso comum da sociedade, procurando trabalhar a educação ambiental de forma holística, participativa, criativa e que valoriza a ação cidadã, onde de acordo com Guimarães (2004, p.30-31):

[...] objetiva promover ambientes educativos de mobilização desses processos de intervenção sobre a realidade e seus problemas socioambientais, para que possamos nestes ambientes superar as armadilhas paradigmáticas e propiciar um processo educativo, em que nesse exercício, estejamos educandos e educadores, nos formando e contribuindo, pelo exercício de uma cidadania ativa, na transformação da grave crise socioambiental que vivenciamos todos.

A Educação Ambiental pode ser explicada em alguns termos que segundo Tanner (1978) contrastam com a concepção conservadora, como o fato da educação ambiental crítica ser abrangente e global; urbana, por tratar também dos aspectos que envolvem a população urbana; por ser universal e se relacionar com as ciências sociais, onde os problemas ambientais necessitam de respostas sociais. Deste modo, Tanner mostra uma educação ambiental com uma nova visão de mundo, onde a transformação da sociedade é fruto de uma relação mútua entre os indivíduos. 
Buscando semelhante leitura da educação ambiental, Mauro Guimarães (2004) nos faz refletir a chamada Educação Ambiental Crítica como um rompimento com os paradigmas da modernidade e com modelo de consumo e desenvolvimento contemporâneo, mostrando que os problemas ambientais resultam da ação humana em sua organização social, gerando como consequência a desigualdade social e a destruição ambiental, procurando mostrar que somos parte e meio ambiente ao mesmo tempo, rompendo com a dualidade homem e meio ambiente e com a visão fragmentada herdada historicamente do cientificismo cartesiano e do antropocentrismo.

A Educação Ambiental Crítica entende a problemática ambiental como uma crise socioambiental, rompendo com a visão de mundo focado nas partes, procurando descortinar essa disjunção através de um movimento dialético de interação entre as partes, através do movimento das partes com o todo e do todo com as partes, trabalhando a educação ambiental de forma complexa, participativa, e que valoriza a ação cidadã. Para romper com esse ideal paradigmático a fim de transformar a sociedade atual, devemos buscar também, como outro caminho, o fortalecimento dos movimentos contra hegemônicos por meio de uma ação conjunta para transformar essa realidade, propondo alternativas que superem os conhecimentos ecologicamente corretos. Deste modo, a Educação Ambiental Crítica:

[...] se propõe em primeiro lugar, a desvelar esses embates presentes, para que numa compreensão (complexa) do real se instrumentalize os atores sociais para intervir nessa realidade. Mas apenas o desvelamento não resulta automaticamente numa ação diferenciada, é necessária a práxis, em que a reflexão subsidie uma prática criativa e essa prática dê elementos para uma reflexão e construção de uma nova compreensão de mundo. Mas esse não é um processo individual, mas que o indivíduo vivencia na relação com o coletivo em um exercício de cidadania, na participação em movimentos coletivos conjuntos de transformação da realidade socioambiental. (GUIMARÃES 2004, p.29)

Portanto, ao entendermos melhor esses dois caminhos que formam a Educação Ambiental, é válido mencionar que no presente trabalho partiremos da ótica da Educação Ambiental Crítica como parâmetro para a discussão das diferentes gestões em que o Projeto Guarda Ambiental Mirim foi/é desenvolvido, buscando o tipo de educação que está sendo desenvolvida no projeto e como ela se apresenta nas práticas realizadas junto às crianças.

Educação e Gestão Ambiental: o caminho para uma gestão de qualidade 
Após um panorama sobre os possíveis caminhos da Educação Ambiental, nos voltaremos para uma concepção de prática educacional relacionada à gestão, para que possamos entender um pouco mais sobre o processo de gestão e como ele pode ser otimizado dentro das Unidades de Conservação.

A gestão e educação ambiental caminham juntas no sentido de proposta da educação ambiental para a gestão pública. Segundo Layrargues (2000) a Educação para a Gestão Ambiental é uma das correntes existentes na Educação Ambiental que pode atender à exigência de se desenvolver uma educação voltada para o exercício da cidadania e de ações coletivas que possam enfrentar os desafios sócio-ambientais. A educação para gestão ambiental exige profissionais qualificados e especializados que obtenham o domínio para processos de ensino-aprendizagem com pessoas em contextos sociais distintos, ela representa, conforme Quintas (2004), uma nova concepção de educação que toma o espaço da gestão ambiental como elemento estruturante na organização do processo ensino-aprendizagem.

O Parque Natural Municipal da Taquara é uma Unidade de Conservação e, de acordo com as exigências do Sistema Nacional de Unidades de Conservação (SNUC), a viabilização de um Conselho é uma proposta que tem por objetivo torná-lo uma instância democrática e legitimada, e fazer com que diferentes agentes sociais participem na gestão do Parque através da tomada de decisões, e criar condições para a realização de uma gestão participativa. Sendo assim, o SNUC propõe a elaboração de uma Gestão Participativa, quando se refere:

as atividades para a criação desses colegiados têm geralmente se constituído em processos restritos a poucas entidades, sendo comum que os convites para a participação sejam direcionados prioritariamente a órgãos públicos e ONGs ambientalistas, cabendo a participação de outras organizações sociais apenas à imposição legal de paridade entre representantes de entidade públicas e da sociedade civil. Mesmo assim, nota-se a tendência para se convidar entidades que representem os interesses empresarias e de segmentos urbanos, em detrimento das formas de organização de moradores e dos produtos mais diretamente relacionados à unidade de conservação. (BRASIL, 2004, p.22)

Há que se considerar, como continua afirmando Quintas (2004), que existem algumas dificuldades encontradas por essas comunidades mais diretamente ligadas à unidade de conservação, onde é limitada a ação efetiva no enfrentamento dos problemas ambientais, pois geralmente possuem um sentimento de incapacidade e impotência diante das grandes forças sociais com maior voz e representação. Já que: 
na vida prática, o processo de apropriação e uso dos recursos ambientais não acontece de forma tranquila. Há interesses em jogo e conflitos (potenciais e explícitos) entre atores sociais que atuam de alguma forma sobre os meios físico-natural e construído, visando o seu controle e ou a sua defesa. (QUINTAS, 2004, p.113)

De acordo com Loureiro (2007), a palavra participação se refere a "tomar parte" no sentido de que é preciso desenvolver ações de mobilização que permitam com que os membros do conselho consigam ter uma intervenção qualificada, principalmente aqueles que não possuem mecanismos de representação política. Ainda sob a mesma perspectiva, Layrargues (2000) refere-se que a participação de diferentes agentes sociais na gestão de uma unidade de conservação está propiciada a diferentes interesses individuais ou coletivos que são representados ás vezes de maneira divergente, sendo importante a necessidade de uma mediação desses conflitos de interesses. É dentro deste contexto que entra o papel da educação e gestão ambiental em frente ao desafio de proporcionar meios de representação política dos diferentes segmentos sociais.

De acordo com Quintas (2004) cabe destacar que é dever do Estado proporcionar um meio ambiente ecologicamente equilibrado como sendo um direito de todos, essenciais à sadia qualidade de vida, baseando-se em uma educação ambiental crítica e emancipatória. Defender esse ambiente implica em criar um estilo de desenvolvimento justo e seguro tanto social quanto ambiental, desenvolver uma gestão ambiental democrática, mediadora de conflitos, fundamentada no princípio de que a gestão ambiental não é neutra, que o Estado deve definir que ficará com o ônus e com o bônus decorrente da ação do homem sobre o meio. Vale considerar que esses custos e benefícios são distribuídos assimetricamente na sociedade, assim como há na sociedade os que possuem mais influência do que os outros. Assim como, é incumbência do Estado:

criar condições para transformar o espaço "técnico" da "gestão ambiental" em espaço público. E dessa forma, evitar que os consensos sejam construídos apenas entre atores sociais com grande visibilidade e influência na sociedade (os de sempre) à margem de outros, em muitos casos os mais impactados negativamente pelo ato do Poder Público. (Quintas, 2004, p.127)

Sendo assim, a Educação no processo de Gestão Ambiental deve proporcionar à participação coletiva e individual na gestão do uso dos recursos ambientais, estruturar o processo educativo tendo em vista a superação da visão fragmentada proporcionando um processo de ação e reflexão em um diálogo tanto com os sujeitos envolvidos quanto 
com outras áreas disciplinares, podendo praticar ações junto com a sociedade civil organizada e com os movimentos sociais, respeitando a diversidade e pluralidade cultural e para a sua melhor eficácia, é preciso conhecer e compreender o meio ambiente e a crise ambiental em sua totalidade, como reflexo das relações sociais e dessas em relação com a natureza. Todos esses fatores são essenciais para praticar a gestão ambiental. E ainda, dar importância a elaboração de conselhos para garantir essa consolidação de espaços públicos e democráticos em uma Unidade de Conservação.

Dentre os pressupostos existentes para a elaboração de conselhos ${ }^{6}$, observa-se um que se destina à elaboração de atividades que permitam a realização de uma Educação Ambiental, quando Loureiro (2007) afirma que é dever do conselho não só o descrito em lei (administrar, avaliar orçamentos e contratos, promover a revisão e desenvolvimento de planos de manejo), mas também potencializar as ações com relação às atividades que visam à proteção e práticas sustentáveis nas Unidades de Conservação. Pode-se perceber, portanto, que além de exigências para a criação de conselhos é preciso, entre os diferentes atores sociais representantes da unidade, entrar em consenso durante a elaboração e criação de mecanismos que potencializam a ação da Educação Ambiental, contribuindo assim, para a formação e o exercício da cidadania na gestão de uma Unidade de Conservação.

\section{Parque Natural Municipal da Taquara: o território dos guardas mirins}

Antes de avançarmos nossas discussões, achamos necessário descrever o espaço no qual as crianças do Projeto Guarda Ambiental Mirim recebem toda a sua formação de guarda ambiental, visto que a maioria delas não mora próxima da Unidade de Conservação, podendo passar a conhecê-la e entendê-la como uma importante área que deve ser preservada, além poderem obter uma nova postura em relação ao parque e a propagá-la para os visitantes, moradores do entorno e a população em geral somente a partir das ideais que são desenvolvidas pelo projeto.

O Parque Natural Municipal da Taquara (PNMT), localizado no bairro da Taquara (Duque de Caxias-RJ), como já foi dito anteriormente, trata-se de uma unidade de proteção integral criada em dezembro de 1992, com cerca de 20 hectares de área

\footnotetext{
${ }^{6}$ Os pressupostos para a estruturação de conselhos poderão encontram-se publicação Educação Ambiental e Gestão Participativa em Unidades de Conservação (Loureiro et al.,2007).
} 
remanescente de Mata Atlântica de responsabilidade gestora da Prefeitura Municipal de Duque de Caxias. A área encontra-se bastante alterada, porém, mesmo assim, apresenta uma diversidade endêmica do bioma em questão, com fauna e flora diversificadas. Sua criação iniciou com a cessão das terras que eram do Instituto Nacional de Colonização e Reforma Agrária (INCRA) à Prefeitura de Duque de Caxias, ocorrendo de forma definitiva em 2006.

Dentre os pontos do parque, destacam-se as quedas d'água, como a Cachoeira Véu da Noiva, e os poços ao longo do Rio das Dores, que atraem uma grande quantidade de pessoas no verão (nessa estação do ano o parque recebe cerca de 5.000 visitantes), além das trilhas que atraem tanto estudantes universitários quanto os moradores da região. Devido a essa quantidade de pessoas que visita o parque, a área também recebe um forte impacto devido à quantidade de lixo deixado e a realização de churrasco, por exemplo. Para amenizar essa situação, há estudantes da Universidade do Grande Rio que fazem mutirões recolhendo o lixo e conscientizando os visitantes, além de trabalharem com pesquisas científicas no parque.

Partindo dessa perspectiva que podemos dizer como é válida a proposta do nosso trabalho, visto que se necessita de um trabalho de educação ambiental conscientizadora e de pensamento crítico, onde o visitante se sinta parte do parque e responsável por mantê-lo o mais preservado possível. Ao mesmo tempo em que as crianças do projeto entendam a importância de uma unidade de conservação, o seu direito e dever como cidadão à manutenção das áreas verdes e consigam realmente se tornar multiplicadores da consciência ambiental que promova a cidadania.

\section{O Guarda Ambiental Mirim: da caracterização às suas diferentes gestões}

Após um panorama sobre as concepções da Educação Ambiental e as características do PNMT nos voltaremos para a atividade educacional, em si, que é desenvolvida no parque, discutindo o seu perfil, método, conteúdo e traçando suas principais características para que no final apresentemos uma avaliação de suas práticas e possíveis motivos que permitiram a permanência do projeto.

O Plano de Manejo do Parque Natural Municipal da Taquara (2004) destaca e encaixa a Educação Ambiental como uma de suas potencialidades, e lhe atribui um caráter fundamental para que se garanta a preservação desta Unidade de Conservação, onde: 
[...] pela sua capacidade natural e instalada, com a presença de equipamentos urbanos associados à beleza cênica do Parque Natural Municipal da Taquara, pode-se dizer que o mesmo apresenta-se com grande potencialidade para o desenvolvimento de atividades de educação ambiental, atingindo todas as idades e classes sociais. (Plano de Manejo, 2004, p. VI-4).

Antes de analisarmos as diferentes gestões, é necessário destacarmos o Projeto Guarda Ambiental Mirim, como já vimos anteriormente, como um projeto de educação ambiental desenvolvido no Parque Natural Municipal da Taquara (PNMT), localizado no $3^{\circ}$ Distrito do município de Duque de Caxias (RJ), que tem como público alvo crianças entre 7 a 14anos da rede municipal e particular e que tem como objetivo formar multiplicadores ambientais.

O Projeto Guarda Ambiental Mirim foi pensado e escrito, segundo Silva (2007), em 2005 pela Diretora do PNMT, o biólogo do parque e por uma professora de Biologia, que trabalhavam no parque na época da gestão 2005-2008, durante o mandato do prefeito Washington Reis de Oliveira. Dois anos depois, foi assinado um convênio entre a Prefeitura e a Petrobrás firmando um financiamento de 800.000 reais para o desenvolvimento do projeto, onde a Organização Não-Governamental (ONG) Iquavi, teria a função de captar e administrar essa verba do projeto.

Durante a gestão 2005-2008, o projeto foi intitulado Guarda Florestal Mirim, com uma duração prevista para 2 anos, iniciando a partir de março de 2007,o curso era dividido em 4 etapas. Cada uma dessas etapas compreende a uma turma, contando com a participação de 4 turmas. Cada etapa estava organizada em cinco níveis que duravam 1 mês cada. Ainda conforme afirma Silva (2007), os níveis de cada etapa apresentavam as seguintes características:

$1^{\circ}$ nível: Soldadinho Verde:

- Desenvolver disciplina em conjunto; conhecer o histórico da Mata Atlântica; obter noções básicas de legislação ambiental; e desenvolver a consciência crítica e ambiental;

$2^{\circ}$ nível: Protetores da Mata:

- Conhecer e respeitar o meio ambiente; identificar espécies mais expressivas da Mata Atlântica; noções de técnicas de reflorestamento; e conhecer a importância da água para a sociedade e para a floresta;

$3^{\circ}$ nível: Defensores da Natureza: 
- Usar mapas e equipamentos de orientação nas florestas; adquirir noções de comportamento em trilhas e manutenção; obter noções básicas de prevenção a incêndios; e conhecer outras áreas de preservação e importância ambiental no município;

$4^{\circ}$ nível: Guardiões do Meio Ambiente:

- Obter noções básicas de primeiros socorros; conhecer os diferentes tipos de queimas, modos de prevenção e noções de regaste; obter noções de orientação aos visitantes do PNMT; e conhecer táticas para salvamento de animais feridos;

$5^{\circ}$ nível: Comandante Mico Leão Dourado ${ }^{7}$ :

- Devem ser capazes de desenvolver as habilidades propostas;

Os níveis acima citados possuíam conteúdos selecionados a partir dos Parâmetros Curriculares Nacionais, do manual do escoteirismo, da Defesa Civil e do Manual de sobrevivência na Selva, segundo Ferreira (2009) os objetivos do projeto também foram elaborados a partir dessa base que servia aos conteúdos, entretanto sua pesquisa não mostra justificativas para o uso dessa base e nem o detalhamento dos conteúdos.

Com base no documento que deu origem ao projeto o objetivo geral tinha o propósito de fundamentar conhecimentos necessários às características, necessidades e valor da Mata Atlântica, levando a reflexão sobre a importância de preservação e restauração das áreas verdes, relacionando-as às questões éticas e filosóficas que norteiam as crianças de suas funções de multiplicadores na comunidade em que vivem e com os visitantes do Parque Natural Municipal da Taquara, no exercício da cidadania e de educadores ambiental. E como objetivos específicos conhecer os princípios básicos de conservação e preservação do meio ambiente no seu município; adquirir conhecimentos técnicos de primeiros socorros, sobrevivência na mata e preservação ambiental, estabelecendo relações interdisciplinares entre esses conteúdos; orientar e informar os visitantes do Parque Natural Municipal da Taquara.

As crianças que participavam nessa época do projeto eram selecionadas por critérios pré-estabelecidos pelo Guarda Florestal Mirim, tais como alta frequência,bom comportamento e notas superiores a 6,para aulas práticas e teóricas que aconteciam

\footnotetext{
${ }^{7}$ O mico leão dourado foi escolhido pela primeira turma para ser a mascote do Projeto Guarda Ambiental Mirim durante a gestão 2005-2008.
} 
duas vezes por semana,tendo um total de 120 crianças divididas entre os turnos da manhã e da tarde.

Em uma entrevista realizada por Ferreira (2009) com a diretora do parque na gestão 2005-2008 se observa que o projeto era visto como prêmio pelas crianças para os melhores e que se eles quisessem participar do mesmo teriam que ser alunos exemplares. Ainda na fala da diretora do PNMT, é feita outra observação, visto que em sua fala é destacada a expressão "modelo positivo", onde se observa que a mesma corresponde ao objetivo de formar lideranças e modelos positivos, durante a formação das crianças no Projeto Guarda Florestal Mirim.

Podemos observar também na pesquisa realizada por Silva (2007) durante essa mesma gestão alguns pontos negativos em relação ao projeto em questão como o fato da disciplina ser a palavra que rege todos os guardas mirins. Em suas entrevistas realizadas com as crianças ela destaca a figura do "aluno-xerife", onde o mesmo tinha a função de se os outros alunos estão seguindo as regras e caso isso não estivesse ocorrendo ele poderia adverti-las verbalmente ou anotava as ocorrências para depois denunciá-las ao professor que poderia tirar pontos dessas crianças, visto que cada criança chegava ao projeto obtendo 10 pontos que poderiam ser perdidos ou não ao longo do mesmo.

Destaca-se também o fato de todos os dias as crianças cantarem o hino nacional organizados em filas e em silêncio, apenas respondendo a comandos de ordem unida, e a condição de expectadores, desenvolvida por parte das práticas. Devido ao destaque a valorização de obediência às regras e a exigência de silêncio absoluto durante as aulas, entende-se que as atitudes tomadas no projeto não contribuem para o desenvolvimento de sujeitos autônomos e críticos, apesar de ser um dos objetos do projeto (Ferreira, 2009).

Ao entrevistarmos um dos secretários de Meio Ambiente ${ }^{8}$ da época, observamos que ele ressalta o caráter comportamentalista do projeto, onde as crianças tinham a postura corrigida e ações controladas, e afirma que o projeto não desenvolveu e nem desenvolve uma prática ambiental de qualidade, mostrando que o trabalho da Educação Ambiental

\footnotetext{
${ }^{8}$ Nesta gestão a Prefeitura de Duque de Caxias contou com a passagem cinco pessoas na função de secretário de Meio Ambiente.
} 
deve ir além do somatório das ações individuais de cuidado ambiental e da imposição de comportamentos ditos "ecologicamente corretos".

Portanto, após as análises dos conteúdos dos trabalhos realizados por Silva (2007) e Ferreira (2009) e entrevistas realizadas, relacionados à gestão 2005-2008 do projeto em questão, podemos observar que se tratava de uma educação ambiental militarizada, como comprovam os próprios nomes "soldadinho" e "comandante", usados para designar os níveis dos conteúdos. Ao mesmo tempo também, podemos considerá-la conservadora, visto que os conteúdos não se relacionam com o cotidiano e com a realidade das crianças, apresentando uma visão compartimentada do ambiente, pensando primeiro na árvore, depois na água e depois nos animais. Logo podemos entender que as crianças eram forçadas a se verem fora do ambiente a ser preservado, através de um afastamento e um não-pertencimento, onde a natureza deveria ser posta como algo intocável e inacessível para continuar existindo.

Apesar da mudança de governo, em 2009, na Prefeitura de Duque de Caxias, onde vale ressaltar a descontinuidade entre os mandatos e a não permanência de alguns projetos executados pelo governo anterior, o projeto de Educação Ambiental desenvolvido no PNMT foi um dos que tiveram sua permanência durante o novo mandato, porém com uma nova equipe na gestão do parque e na coordenação do projeto, que proporcionaram modificações no mesmo.

Na gestão 2009-2012, mandato do prefeito José Camilo dos Santos Filho, destaca-se, segundo entrevista realizada com o gestor e com a atual coordenadora do projeto de educação ambiental, que o mesmo tem como objetivo desenvolver uma formação ambiental voltada para preservação e respeito ao meio ambiente, além de formar multiplicadores de uma nova consciência ecológica, no qual podemos dizer que o objetivo do projeto formulado na gestão anterior foi mantido. Entretanto, o nome, o número de alunos, a disposição dos conteúdos e algumas outras mudanças na dinâmica do projeto fazem parte das modificações realizadas nessa nova gestão.

Com destaque para essas mudanças, podemos dizer que atualmente o projeto atende com o nome de Projeto Guarda Ambiental Mirim, através de uma parceria junto à Secretaria Municipal de Educação de Duque de Caxias, cerca de 240 crianças por ano da rede municipal, particular e estadual de ensino, que são conduzidas ao parque duas 
vezes por semana para aulas teóricas e práticas, onde são divididos em dois grupamentos, um de manhã e outro à tarde, com 60 alunos cada grupamentor. Neste momento podemos observar que o número anual de crianças dobrou e se estendeu para os alunos das escolas estaduais, ampliando o público-alvo dos multiplicadores ambientais.

Nessa nova gestão formam-se quatro turmas durante o ano, onde o curso tem duração de 3 meses e é dividido em módulos, substituindo os níveis da gestão anterior, com diferentes temas cada. Segundo nossa entrevista realizada com a atual coordenadora do projeto, a Secretaria Municipal de Educação manda o currículo escolar e algumas sugestões relacionadas a temática ambiental ,como por exemplo, em 2010 o enfoque foi para o descarte ideal do lixo, então a partir disso se resolveu a divisão em módulos. Os conteúdos abordados são:

\section{Primeiro Módulo:}

- Cidadania e Disciplina;

- Conhecer e Respeitar o Espaço Coletivo;

- Alimentação Alternativa;

- Significado do Hino Nacional;

- Noções Básicas de Primeiros Socorros;

- Escoteiros;

\section{Segundo Módulo:}

- Histórico da Mata Atlântica;

- Biomas;

- Plantas Tóxicas;

- Plantas Medicinais;

- Animais Peçonhentos; 
- Prevenção de Incêndios;

- Orientação e Mapas;

\section{Terceiro Módulo:}

- Consciência Crítica e Ambiental;

- Técnicas de Reflorestamento;

- Cuidados com a Fauna;

- Noções Básicas da Legislação Ambiental.

Podemos observar que os módulos são organizados por conteúdos, onde o primeiro módulo está relacionado basicamente à disciplina, patriotismo e conduta, já o segundo módulo pode ser compreendido basicamente pelos conteúdos ecológicos, sobrevivência na mata e prevenção de incêndios, e o terceiro módulo está relacionado à legislação e “práticas verdes". Há também a realização de palestras de diversas temáticas que não estão mencionadas necessariamente nos módulos, como por exemplo, palestras sobre a dengue e a febre aftosa.

Com a relação ao conteúdo abordado no Guarda Ambiental Mirim podemos avaliar que não está realmente preocupado com a temática da problemática ambiental, pois os conteúdos não buscam esse problema, suas causas, consequências e possíveis maneiras de solucioná-la ou amenizá-la. Podemos dizer que os conteúdos estão mais relacionados ao escoteirismo do que a temática ambiental em si, podendo até sugerir que não se trata de uma educação ambiental e sim um treinamento para futuros guardas-florestais, o que não é essa a ideia do projeto.

A equipe do projeto atualmente é composta pelo diretor do parque, engenheiro agrônomo, especializado em Ciências Ambientais, a coordenadora do Projeto Guarda Ambiental Mirim, pedagoga, especializada em psicopedagogia e em administração, e um professor de história cedido pela Secretaria Municipal de Educação (SME), além de 
voluntárias e estagiárias de gestão ambiental do Processo APELL ${ }^{9}$, um movimento social, que ajudam a organizar as crianças dentro da sala de aula, trilhas e passeios.

Na gestão 2009-2012 ocorreu o término e a não renovação do contrato, em 2009, entre a Prefeitura e a Petrobrás, onde a partir de então o projeto passou a contar com parceiros. Segundo entrevistas feitas com a atual equipe do projeto, o mesmo possui parceria com o transporte e com o lanche distribuído para as crianças, fornecido pela empresa Mabel, além da parceria com a Universidade do Grande Rio (UNIGRANRIO) que disponibiliza biólogos voluntários, com a Defesa Agropecuária do Estado, o Instituto de Educação e Saúde da Taquara (IEST) e o Corpo de Bombeiros de Magé que disponibilizam pessoas para realizarem as palestras já mencionadas.

A seleção das escolas que contemplam o projeto é feita metade pela direção do parque, metade pela Secretaria de Educação. Segundo a coordenadora do projeto, a escolha dos alunos cabe ao corpo docente das escolas, mas a partir de alguns pré-requisitos determinados pelos diretores do Projeto Guarda Ambiental Mirim, como a de que os alunos devem estar alfabetizados, possuir um perfil de líder, interessado em assuntos relacionados ao meio ambiente, mostrando outra mudança realizada pela gestão 20092012, pois os critérios anteriores eram baseados nos bons alunos, entretanto, atualmente participam também do projeto crianças indisciplinados ou com algum déficit escolar. As escolas selecionadas para o segundo semestre do ano de 2011 que pertencem ao $2^{\circ}$ e $3^{\circ}$ Distritos de Duque de Caxias foram as seguintes:

Escolas Municipais:

- Escola Municipal Montese;

- Escola Municipal Luiz Gama Borges;

\footnotetext{
${ }^{9}$ O Processo APELL é um conjunto de diretrizes formuladas pelo Departamento da Indústria e Meio Ambiente do Programa das Nações Unidas para o Meio Ambiente (UNEP), em cooperação com a Associação das Indústrias Químicas dos Estados Unidos e o Conselho Europeu das Federações da Indústria Química, com dois objetivos básicos: 1)Criar e/ou aumentar a conscientização da comunidade quanto aos possíveis perigos existentes na fabricação, manuseio e utilização de materiais perigosos e quanto às medidas tomadas pelas autoridades e indústria no sentido de proteger a comunidade local; 2)Desenvolver, com base nessas informações, e em cooperação com as comunidades locais, planos de atendimento para situações de emergência que possam ameaçar a segurança da coletividade.
} 
- Escola Municipal Marilândia;

- Escola Municipal Monteiro Lobato.

Escolas Estaduais:

- Escola Estadual Professora Maria Anger Dias Guarino;

- Escola Estadual Minervina Barbosa de Castro.

Acompanhamos esses alunos durante algumas aulas para entendermos a dinâmica do projeto na prática, com isso destacamos determinados pontos que observamos nessas aulas. As aulas se apresentam na teoria, onde as crianças ficavam numa espécie de sala de aula com a coordenadora, o professor de história ou o palestrante ministrando a aula, e na prática, correspondendo às trilhas realizadas dentro do parque e as aulas realizadas em outros lugares, como por exemplo, no Corpo de Bombeiros de Magé.

Durante as aulas teóricas notamos que era exigido um comportamento por parte dos alunos, em que eles não poderiam conversar entre si em nenhum momento e caso isso acontecesse, eram chamados à atenção severamente ou sofriam ameaças de suspensão. Além disso, para voltar à atenção das crianças eram utilizados espécies de comandos de ordem unida, onde os alunos as respondiam em uma única voz, como uma espécie de tropa respondendo ao comando de algum superior, um exemplo disso, foi o momento em que a coordenadora dizia "atenção" e os alunos respondiam em uma só voz e num forte tom "muita atenção"

As crianças eram conduzidas a se sentarem corretamente e a permanecerem sentadas para não sofrerem advertência. A sala era dividida ao meio, onde de um lado sentavam as meninas e do outro os meninos, a opinião das crianças e seus questionamentos não eram fundamentais para a dinâmica da aula, pois eram apenas espectadores de um professor ou o palestrante que era visto como o possuidor de todo o conhecimento, enquanto os alunos, como pacientes, não tinham nada a acrescentar nessa ação.

Já as aulas práticas divididas nas trilhas e nas visitas a outros lugares, poderiam ser questionadas da seguinte maneira: as trilhas realizadas no próprio parque não acrescentavam muito à formação de conhecimento das crianças, porque o professor, por não ter um conhecimento acadêmico, visto que ele é um historiador, não sabia 
responder muitas das indagações das crianças, como por exemplo, o fato dele não saber dizer o nome das plantas que davam algumas das sementes que eles encontraram durante uma caminhada pelo parque. E nas visitas, as crianças eram recebidas por um representante do local que explicava para elas o que estavam fazendo naquele local e o que iriam aprender, apresentando um preparo maior para responder as dúvidas dos alunos.

Os banhos de cachoeira, realizados uma vez por mês, eram somente para lazer das crianças do projeto, em que eles eram orientados a "não usar loção de bronzear ou qualquer outro produto químico porque poderiam contaminar a água", explicava a coordenadora do projeto. Nesse dia não há nenhuma atividade educacional com as crianças.

A saída das crianças também era um motivo para chamar a atenção das crianças, elas eram chamadas por escola e em seguida se levantavam e formavam uma fila em frente à porta e só poderiam sair quando estivessem autorizadas, caso alguém ficasse conversando ou fazendo algo que fosse considerado um incomodo para a coordenadora ou para o professor, o mesmo era colocado no final da fila e era o último a sair, sofrendo uma espécie castigo. Quando chegavam ao ônibus que as conduziam de volta para as escolas, era escolhido o "monitor do lixo", responsável por recolher o mesmo dentro do ônibus, no qual as crianças ficavam animadas para serem escolhidas.

Até aqui, observamos que o projeto de educação ambiental não se apresenta como uma referência, por apresentar um perfil repressor e despreparado. A educação ambiental desenvolvida pode ser considerada uma Educação Ambiental Conservadora por oferecer uma proposta fragmentada do ambiente, ao mesmo tempo em que não procura romper com o paradigma em que está mergulhada a sociedade atual.

Além de observar as aulas, realizamos algumas atividades com os alunos do Guarda Ambiental Mirim, onde em uma atividade em que eles teriam que desenhar elementos do parque, observamos que $60 \%$ das crianças possuem um pensamento de natureza idealizada ao desenhar o PNMT e 40\% desenharam elementos do parque em uma natureza idealizada, mostrando que a ideia de Mata Atlântica e sua importância não são bem trabalhadas. 
Outra atividade realizada foi a aplicação do jogo "Em Construção", jogo desenvolvido pelo NIESBF, onde as crianças seriam as gestoras das suas cidades e teriam que tomar algumas decisões para torná-la sustentável. Neste dia o nosso objetivo era entender a concepção de natureza das crianças do projeto e como retorno dessa atividade observamos que as crianças possuem uma visam fragmentada de ambiente, além de entenderem que apenas jogar o lixo no local certo, não poluir os rios e não cortar árvores é o suficiente para vivermos de forma sustentável e saudável, visto que a crise ambiental não está relacionada somente a esses fatores, mas também o da degradação humana junto ao ambiente, pois a noção que deve ser passada é a de que os problemas ambientais resultam da ação humana e de sua organização social, e que por isso é necessário pensar nos valores que regem a nossa vida cotidiana e global e na verdadeira noção de meio ambiente, em que o homem é ao mesmo tempo parte e meio ambiente.

\section{Conclusão}

Os questionamentos levantados no presente artigo mostram que as duas gestões aparentam ter um mesmo perfil de educação ambiental, em que meio ambiente se resume a uma natureza intocável e sagrada, onde o homem é um ser a parte dessa realidade, reforçando os paradigmas que influenciam a sociedade moderna, visto que os dois momentos do projeto apresentam um conteúdo focado somente no conhecimento ecológico, que consequentemente reproduz uma limitação compreensiva de meio ambiente e uma incapacidade de argumentação das crianças por conta do caráter militarizado.

A permanência desse perfil se deve ao fato de que as mudanças realizadas no projeto durante a troca de gestão não modificaram sua base, mas apenas aumentaram o contingente de alunos e elaboraram um novo arranjar dos conteúdos, mas sem alterá-lo na essência, permitindo dizer uma aparente continuidade de conduta ambiental ao longo das gestões aqui discutidas, o que garantiu a continuidade do projeto.

Observamos também que nenhuma das gestões permitiu um melhor aproveitando do fato de ser uma educação ambiental desenvolvida dentro de uma Unidade de Conservação, visto que não é explorada a importância de um Parque Natural e sua importância para a o próprio município. Ao mesmo tempo em que não explorada a interlocução com os moradores do entorno, visto que o projeto compreende um número 
inexpressivo de crianças da localidade, somente no momento em que o Distrito ao qual pertence a área é escolhido, mostrando que a falta de participantes e conteúdos sobre este território não ajuda a minimizar os impactos sofridos pelo mesmo, pois a população continua a rejeitar o mesmo por falta de conhecimento.

Com relação a dinâmica do projeto, podemos concluir que ela está baseada em critérios que não induzem os alunos a trabalhar coletivamente por conta da exacerbada ênfase na disciplina e a não interação entre os alunos, desenvolvendo uma didática primitiva em que os alunos não são estimulados a expressar sua opiniões e a participar ,de forma ativa, das aulas.

Os conteúdos abordados durante os dois momentos do projeto expõe o fato de que eles devem ser repensados em sua essência, pois o fato de saber identificar plantas nocivas, socorrer pessoas na mata e saber o hino nacional não o caracterizam como educação ambiental, levando-nos a indagar sobre o despreparo desses profissionais com relação a temática ambiental e educação. Esta indagação nos leva ao resultado de uma formação, não de multiplicadores da consciência ambiental, mas de verdadeiros escoteiros que estão prontos a para tornarem simples guias das trilhas do parque.

Logo, o que sobra para se trabalhar com uma temática mais ambiental, porém sempre no caráter ecológico, não é desenvolvido com qualidade por conta da limitação do saber, gerando um conhecimento alienado e reduzido dos problemas ambientais, voltada para a Educação Ambiental Conservadora que traz o ambiente compartimentado em elementos ecológicos e uma visão de "salve o planeta" limitada a estes.

Todos estes fatores constam que a "prática ambiental" desenvolvida pelos alunos acontecerá em regime de ação individual, perdendo totalmente o objetivo de "multiplicadores", não contribuindo de fato para a melhoria da crise ambiental e a para a construção de outro conceito de meio ambiente, onde o consumismo, a exploração de forma extrema, a degradação humana e ecológica e os valorização dos fatores econômicos acima dos sociais sejam banidos da sociedade atual para que se construa um verdadeiro meio ambiente sustentável.

O produto gerado nessa discussão procurou contribuir como informação sobre o tipo de educação ambiental que está sendo desenvolvida em nosso município, onde o projeto em questão não se apresenta como um modelo a ser seguido, ao mesmo tempo em que 
procura servir como um alerta para a próxima gestão, para que o projeto não cometa os mesmos erros e não possua o mesmo perfil, pois as questões a cerca do ambiente são complexas, onde é necessário o desenvolvimento de um olhar holístico e a busca de elos para que se construa uma verdadeira educação ambiental, sustentada pelo trabalho coletivo, pelo pertencimento ao ambiente e por verdadeiros valores que melhorem a condição humana.

\section{Referências Bibliográficas}

BRASIL. Lei $\mathbf{n}^{0}$ 9.985, de 18 de julho de 2000.

Ministério do Meio Ambiente. Programa Nacional de Educação Ambiental. Brasília, 2003.

Ministério do Meio Ambiente. Gestão Participativa do

SNUC. Brasília, 2004.

ECP-Consultoria e projeto Ltda. Plano de Manejo do Parque Natural Municipal da Taquara. Rio de Janeiro, 2004.

FERREIRA, Graziele Cristina Braga. Educação Ambiental e Ensino de Ciências: uma proposta integradora para a Escola e o Parque Natural Municipal de Taquara/RJ. 2009.119f. Dissertação (Mestrado em Educação), Centro Universitário Plínio Leite, Niterói, 2009.

GUIMARÃES, Mauro. A dimensão da Educação Ambiental na Educação. Rio de Janeiro: Papirus, 2000.

Educação Ambiental Crítica. In: Identidades da educação ambiental brasileira / Ministério de Meio Ambiente. Diretoria de Educação Ambiental; Philippe Pomier Layrargues (coord.). Brasília: Ministério do Meio Ambiente, 2004.p. 25-34.

LAYRARGUES, P. P. Educação para a gestão ambiental: a cidadania no enfrentamento político dos conflitos socioambientais. In: LOUREIRO, C. F. B. (Org.). Sociedade e meio ambiente: a educação ambiental em debate. São Paulo: Cortez, 2000. p. 87-155.

LOUREIRO, C. F. B. Educação ambiental e conselho em unidades de conservação: aspectos teóricos e metodológicos / Carlos Frederico B. Loureiro, Marcus Azaziel, NahydaFranca. - Ibase: Instituto TerrAzul: Parque Nacional da Tijuca, 2007. 
QUINTAS, J. S. Educação no processo de gestão ambiental: uma proposta de educação ambiental transformadora e emancipatória. In Identidades da educação ambiental brasileira / Ministério de Meio Ambiente. Diretoria de Educação Ambiental; Philippe Pomier Layrargues (coord.). Brasília: Ministério do Meio Ambiente, 2004. p.113-140.

RUSCHEINSKY, A. e colaboradores. Educação Ambiental: abordagens Múltiplas. Porto Alegre: Artmed, 2002.

SILVA, Viviane Aparecida. A Relação entre a Educação Ambiental Formal e Não Formal: Um Estudo de Caso do Parque Natural Municipal da Taquara e as Escolas do entorno. 2007.80f. (monografia) - Faculdade de Educação da Baixada Fluminense, Universidade do Estado do Rio de Janeiro, Duque de Caxias, 2007.

TANNER, R. T. Educação Ambiental. Tradução SCHLESINGER, G. São Paulo: SUMUS E EDUSP, 1978. 